\title{
Value of the Resting Electrocardiogram in Assessing Patients with Recent Onset Chest Pain A Study in Tertiary Care Hospital, Dhaka Bangladesh
}

\author{
Roy US ${ }^{1}$, Khan MMR ${ }^{2}$, Bhowmik TK ${ }^{3}$, Sarker RN, ${ }^{4}$ Sarker NR ${ }^{5}$
}

Conflict of Interest: None Received: $17-10-2017$

Accepted: $12-11-2017$ www.banglajol.info/index.php/JSSMC

Key Words: Resting

Electrocardiogram, Onset Chest Pain

\begin{abstract}
Background: Chest pain or discomfort caused by acute coronary syndrome (ACS) or angina has a potentially poor prognosis, emphasizing the importance of prompt and accurate diagnosis. To evaluate a clinic set up specifically to assess patients with recent onset chest pain, particularly those presenting with a normal resting electrocargram.
\end{abstract}

Method: The cross-sectional study was carried out from September 2016 to August 2017 in cardiology department of Shaheed Suhrawardy Medical College hospital, Sher-E-Bangla Nagar, Dhaka. Total 1000 consecutive patients with recent onset chest pain were evaluated within 24 hours of general practitioner referral, to find out the clinical diagnosis and management.

Results: Total 1000 patients (535 men and 465 women, mean age $51.5 \pm 11.4$ years with range from 32 to 70 years) were assessed over 12 months. Most of the patients 844 (84.4\%) had symptoms in duration of $\leq 30$ days. Majority 433 (43.3\%) patients had peptic ulcer disease (PUD), 317 (31.7\%) patients had chronic stable angina (CSA), 94 (9.4\%) had unstable angina (UA), 92 (9.2\%) had anxiety neurosis (AN) and 64 (6.4\%) had myocardial infarction (MI). Regarding outcome of the patients 525 (52.5\%) [PUD: 433+ AN: 91] patients considered to have noncardiac pain and referred to medicine outpatient department (OPD) without further follow up. In a further 317 patients $(31.7 \%$, CSA) arrangements were made for outpatient review. Ninety four patients $(9.4 \%, U A)$ were referred to National Institute of Cardiovascular diseases (NICVD) for admission out of them 61 patients were admitted for medical treatment \& 33 patients were discharged from emergency department whose troponin-I were negative. Remaining 64 (6.4\%) acute MI patients were admitted into Coronary Care Unit (CCU) of NICVD, out of them 41 patients received streptokinase injection, 23 patients received Enoxaparin injection, after conservative treatment all patients were advised to do coronary angiography within 3 to 4 weeks.

Among these 43 patients underwent coronary angiography within 4 weeks, 23 patients had coronary angioplasty, eleven patients had coronary bypass surgery and nine patients refused any intervention and discharged with medicine.

Conclusion: This experience highlights the inadequacy of a routine electrocardiogram reporting service in patients with recent onset of chest pain. Clinical diagnosis found were peptic ulcer disease (PUD), chronic stable angina (CSA), unstable angina (UA), anxiety neurosis and myocardial infarction (MI). Regarding outcome of the patients were coronary angiography followed by coronary angioplasty, coronary artery bypass surgery, discharged with medicine and referred to out patients department of medicine unit.

[J Shaheed Suhrawardy Med Coll 2017; 9(2): 65-68] DOI: http://dx.doi.org/10.3329/jssmc.v9i2.37265

1. Dr. Udoy Shankar Roy, Associate professor, Department of Cardiology, Shaheed Suhrawardy Medical College (ShSMC) Dhaka, Bangladesh

2. Dr. Md. Murshidur Rahman Khan, Asstt. Prof. Cardiology dept. (ShSMC)

3. Dr. Tapas Kanti Bhowmik, Asst. Prof. Cardiology, Sheik Hasina Medical College, Tangail

4. Dr. Ramendra Nath Sarker, Associate Prof. Cardiology, Rangpur Medical College.

5. Dr. Nihar Ranjan Sarker Assoc. Prof. Paediatric dept. (ShSMC) Correspondence to: Dr. Udoy Shankar Roy, Associate professor, Department of Cardiology, Shaheed Suhrawardy Medical College (ShSMC) Dhaka, Bangladesh, e-mail: drudoys@gmail.com

\section{Introduction:}

Diagnosis of recent onset chest pain or discomfort of suspected cardiac origin depends on a number of factors. These include the person's history of chest pain, their cardiovascular risk factors, history of ischaemic heart disease and any previous treatment, and previous investigations for chest pain. ${ }^{1}$

The value of the resting electrocardiogram in patients with suspected acute infarction is clear. Chest pain is a common presentation in general practice: in the UK, up to $1 \%$ of 
visits to a GP are due to chest pain. ${ }^{2}$ Chest pain matters: the risk of death is doubled in the year following a new

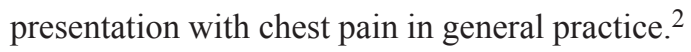

Heart rate (HR) is a prognostic marker that is increasingly used as a therapeutic target in patients with cardiovascular disease. The association between resting and mean HR remains unclear.

The value of an immediate ECG is given prominence, particularly in distinguishing those patients who require emergency transfer to hospital from those patients who need urgent (same-day, but not emergency) assessment. This may encourage some practitioners and providers to increase the availability of immediate ECGs. For chronic chest pain, the recommendations are quite sweeping and are likely to have major effects both in general practice and in chest pain clinics. The extent to which the investigation of chronic stable chest pain occurs in general practice is likely to become clearer as the guideline is implemented. ${ }^{3}$

\section{Materials and Methods:}

The cross-sectional study was carried out in cardiology department of Shaheed Suhrawardy Medical College Hospital, Sher-E-Bangla Nagar, Dhaka from September 2016 to August 2017. Total 1000 consecutive patients with recent onset chest pain were seen within 24 hours of general practitioner referral to find out the clinical diagnosis and management. General practitioners were encouraged to telephone the on-call cardiology registrar to discuss the case before sending the patient to the clinic which was available between 2 and 4 pm every week day. All patients were seen on the day of referral and assessed by a cardiology registrar or senior registrar who recorded the clinical diagnosis based on the history, physical examination, and resting electrocardiogram. Unstable angina was defined as any deterioration in the pattern of previously stable symptoms, rest pain, or only exertional symptoms if they had been present for less than two weeks. Significant coronary disease was defined angiographically as a $50 \%$ or greater reduction in luminal diameter of at least one major coronary vessel.

\section{Results:}

Out of 1000 patients, $351(35.1 \%)$ patients belonged to age $51-60$ years. The mean age was found $51.5 \pm 11.4$ years with range from 32 to 70 years (Table 1). 535(53.5\%) patients were male and 465(46.5\%) patients were female. Male female ratio was 1.15:1 (Figure 1). Majority 844(84.4\%) patients had symptoms in duration of $\leq 30$ days (Table 2 ).

Table-I

Distribution of the study patients by age $(n=1000)$

\begin{tabular}{lcc} 
Age (in year) & No. of patients & Percentage \\
\hline d"40 & 240 & 24.0 \\
$41-50$ & 180 & 18.0 \\
$51-60$ & 351 & 35.1 \\
$>60$ & 229 & 22.9 \\
Mean \pm SD & \multicolumn{2}{c}{$51.5 \pm 11.4$} \\
Range (min-max) & \multicolumn{2}{c}{$32-70$} \\
\hline
\end{tabular}

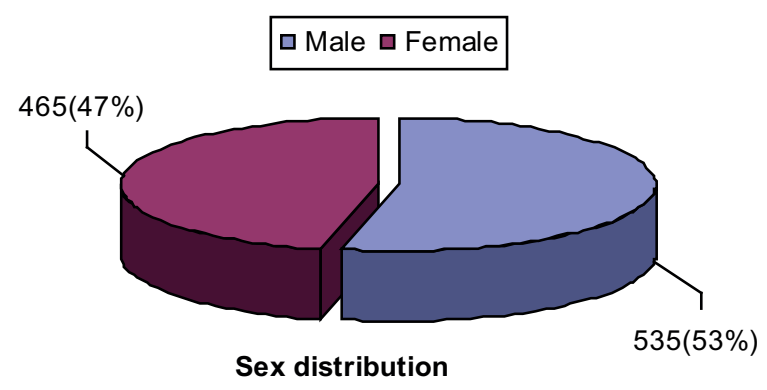

Fig.-1: Sex of the study patients $(n=1000)$

Table-II

Duration of symptoms of the study patients $(n=1000)$

Duration of symptoms No. of patients Percentage (days)

\begin{tabular}{lll}
\hline$\leq 30$ & 844 & 84.4 \\
$>30$ & 156 & 15.6 \\
\hline
\end{tabular}

Regarding risk factors of the patients, it was observed that majority $389(38.9 \%)$ of the patients were smoker, $300(30.0 \%)$ patients had hypertension, $289(28.9 \%)$ had H/ O IHD, 160(16.0\%) had dyslipidemia and 29(2.9\%) had diabetes mellitus (Figure 2).

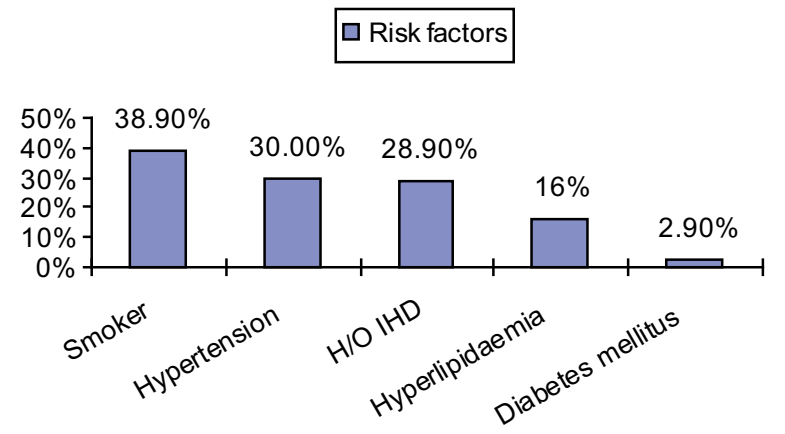

Fig.-2: Risk factors of the study patients $(n=1000)$ 
In this study majority 433(43.3\%) patients had peptic ulcer disease (PUD), 317(31.7) patients chronic stable angina, $94(9.4 \%)$ had unstable angina, $92(9.2 \%)$ had anxiety neurosis and $64(6.4 \%)$ had myocardial infarction (Table III).

\section{Table-III}

Clinical diagnosis of the study patients $(n=1000)$

\begin{tabular}{lcc} 
Clinic diagnosis & No. of patients & Percentage \\
\hline Chronic stable angina & 317 & 31.7 \\
Unstable angina & 94 & 9.4 \\
Myocardial infarction & 64 & 6.4 \\
Peptic ulcer disease (PUD) & 433 & 43.3 \\
Anxiety neurosis & 92 & 9.2 \\
\hline
\end{tabular}

Regarding outcome of the patients, it was observed that 525(52.5\%) \{PUD: 433+AN: 91$\}$ patients had non-cardiac pain and referred to medicine outpatient department (OPD), $317(31.7 \%)$ had Chronic stable angina and treated conservatively and $94((9.4 \%)$ patients had unstable angina referred to outpatients department of National Institute of Cardiovascular Disease (NICVD) and remaining 64 (6.4\%) patients had acute myocardial infarction (MI) and also referred to emergency department of NICVD (Table-IV).

\section{Table-IV}

Outcome of the study patients $(n=1000)$

\section{Outcome}

No. of patients Percentage

Non-cardiac pain and $525 \quad 52.5$

referred to medicine

outpatient department (OPD)

Chronic stable angina 317 31.7 and treated conservatively

Unstable angina referred 94 9.4

to outpatients department Acute myocardial infarction(MI) and also referred to emergency department of NICVD.

\section{Discussion}

In this study it was observed that 351 (35.1\%) patients belonged to age 51-60 years. The mean age was found $51.5 \pm 11.4$ years with range from 32 to 70 years. Dougan et al. ${ }^{4}$ study found that the mean (SD) age of 53(13) years. Norell et al. ${ }^{5}$ study showed the mean age 58 years (range $25-84$ years). Santos et $\mathrm{al}^{6}$ study observed that the mean age was found 54.0 years $( \pm 18.5)$.
In current study we observed that 535(53.5\%) patients were male and 465(46.5\%) patients were female. Male female ratio was $1.15: 1$. In study of Santos et $\mathrm{al}^{6}$ observed that males were found $45.2 \%$. Norell et $\mathrm{al}^{5} 176(70.4 \%)$ men and $74(29.6 \%)$ women. Dougan et al. ${ }^{4}$ observed that out of these $709,401(57 \%)$ were male.

In this study showed majority $844(84.4 \%$ ) patients had symptoms in duration of $\leq 30$ days. Norell et al. ${ }^{5}$ the mean duration of symptoms precipitating referral was 27 days (range 1-90 days). One hundred and eighty seven patients (75\%) presented within- 30 days of the onset of symptoms and $100(40 \%)$ were assessed within seven days.

Regarding risk factors of the patients, it was observed that majority 389(38.9\%) patients were smoker, 300(30.0\%) patients had hypertension, 289(28.9\%) had H/O IHD, $160(16.0 \%)$ had dyslipidaemia and $29(2.9 \%)$ had diabetes mellitus. Santos et al. ${ }^{6}$ study observed that current smokers were $12.8 \%$, hypertension 38.8 , hyperlipidaemia $34.0 \%$ and diabetes mellitus $2.7 \%$. Dougan et al. ${ }^{4}$ study showed current smokers was 252(36\%), hypertension $180(25.0 \%)$, Only $12(18 \%)$ had a previous history of ischaemic heart disease, dyslipidaemia 155(22.0\%) and diabetes mellitus $5.0 \%$.

In this study majority 433 (43.3\%) of the patients had peptic ulcer disease (PUD), 317(31.7\%) patients had chronic stable angina, 94(9.4\%) had unstable angina, 92(9.2\%) had anxiety neurosis and 64(6.4\%) had myocardial infarction. Autore et al. ${ }^{7}$ found that electrocardiogram provides a specific diagnosis only in $4.9 \%$ of patients with acute myocardial infarction. Norell et al. ${ }^{5}$ study reported that sixty nine patients $(37.5 \%)$ were considered to have non-cardiac pain. In 317 cases $(31.7 \%)$ the diagnosis was stable angina and 94 patient's symptoms were considered to represent unstable angina, despite a normal resting electrocardiogram in 21 patients. Sixty four patients (6.4\%) presented with myocardial infarction. This experience highlights the potential dangers associated with the finding of a normal resting electrocardiogram in patients with suspected unstable angina. In a practice serving 2500 patients, a general practitioner may see up to 100 patients with chest pain per year. ${ }^{8}$ A diagnosis of acute myocardial infarction was made in only six cases despite referral of patients specifically with suspected cardiac symptoms. However, the population assessed in our cardiology department was selected after discussion with the general practitioner in each case. Because patients were to be seen in an outpatient department we believed that in those cases where the diagnosis of acute myocardial infarction was likely the general practitioner would be better advised to send the patient to the nearest accident and emergency department. There, full resuscitative facilities would be immediately available on arrival if required. 


\section{Conclusion:}

This experience highlights the inadequacy of a routine electrocardiogram reporting service in patients with recent onset of chest pain. Clinical diagnosis was found peptic ulcer disease (PUD), chronic stable angina, unstable angina, anxiety neurosis and myocardial infarction. Regarding outcome of the patients were coronary angiography followed by coronary angioplasty, coronary artery bypass surgery, discharged and patients referred to outpatients department of medicine unit. For proper evaluation of chest pain, besides ECG, Echocardiogram, exercise tolerance test (ETT), Troponin-I \& finally Angiocardiogram may be needed.

\section{References:}

1. Chest pain of recent onset: assessment and diagnosis, https:/ /www.nice.org.uk/ guidance/ cg95/chapter/Context 2016

2. Ruigomez A, Rodriguez LA,Wallander MA, et al. Chest pain in general practice: incidence, comorbidity andmortality. Fam Pract 2006; 23(2): 167-174.
3. NICE clinical guideline: chest pain of recent onset, British Journal of General Practice 2010; 60: 607-610

4. Dougan JP, Mathew TP, Riddell JW, Spence MS, McGlinchey PG, Nesbitt GS et al. Suspected angina pectosis: a rapid-access chest pain clinic. Q J Med 2001; 94: 679-683.

5. Norell M, Lythall D, Coghlan G, Cheng A, Kushwaha S, Swan J, Ilsley C, Mitchell A. Limited value of the resting electrocardiogram in assessing patients with recent onset chest pain: lessons from a chest pain clinic. Br Heart J 1992; 67: 53-6

6. Santos P, Martins C, Pessanha P, Viana M, Sa L, Hespnhol A, Pereira AC et al. Electrocardiogram and Chest pain in Real Practice: A Retrospective Cohort Study in Family Practiction Portugal. Research Journal of Medical Sciences 2015; 9(3): 58-63.

7. Autore C, Agati L, Piccininno M, Lino S and Musaro S. Role of Echocardiography in Acute Chest Pain Syndrome. The American Journal of Cardiology 2000; 86(4A): 41G-42G.

8. Mead M, Paterson H. Tutorials in general practice. London: Pitman, 1983. 